\title{
Maintaining Low Resistance in Conductive Joints
}

\author{
Samarjit Bhattacharyya, Anandita Chowdhury, Hitesh R. Jariwala, M Sharaschandra Shetty, and \\ Rajulkumar Engineer
}

\begin{abstract}
In the electric power industry, optimizing power flow is a primary concern, in the generation, transmission and distribution process. One key ingredient is providing and maintaining low resistance conductive joints. Field experience and laboratory studies have shown that this is especially true in the case of bus bars and bolted high current connections. Unplated joints are generally less reliable due to potential oxidation of the surfaces. If unplated joints are used special care must be taken to clean the two surfaces and petroleum based greases should be applied to slow down the oxidation process. The development of Belleville washers permitted some significant advances in the ways busbars could be joined. This paper describes how plated bus bars outperform unplated bus bars by providing stable contact resistance and a low maximum operating temperature that will increase the service life of the bus joint.
\end{abstract}

Index Terms-Aluminum bus bar, belleville washer, copper bus bar, contact resistance, , silver plating

\section{INTRODUCTION}

Earlier in the electric power industry the aluminum or copper bus bars were installed uncoated and left that way. While the performance of an uncoated bus joint may have been sufficient years ago, today's increasing demands for power, given the limited capacity and economies of the marketplace, are forcing the producers to improve the efficiency and performance of the entire system. Engineering surfaces are never absolutely smooth and the surface irregularities become apparent when observed under a microscope. As a result, constriction resistance arises in practical electrical interfaces because contact is made only at few discrete spots as defined by the roughness of contacting surfaces and applied contact pressure

The resistance of a joint [1] is affected mainly by two factors:

a) Streamline effect or spreading resistance Rs, the diversion of the current flow through a joint.

b) The contact resistance or interface resistance of the joint $R i$.

The total joint resistance $R j=R s+R i$

The above equation is valid only for a $d . c$ current. Where a.c. currents are flowing, the changes in resistance due to proximity and skin effects in the joint zone will also be taken

Manuscript received July 6, 2011; revised August 12, 2011.

Samarjit Bhattacharyya, Anandita Chowdhury, and Hitesh R. Jariwala are with Department of Electrical Engineering of S. V. National Institute of Technology, Surat.india.

M Sharaschandra Shetty and Rajulkumar Engineer are with Reliance Industries Limited, Hazira, Surat, Gujarat, India. into account.

Further the role of changes in thermal and electrical resistance that can occur in a clamped joint is very important as both can affect the contact force and current flow across the joints A purely metallic contact joint occurs only in vacuum. In free air oxide layers form on the contact surfaces. The hardness of the contact material also affects the resistance to current flow across the joint [2]. A microscopic view (Fig. 1) of the contact surfaces shows that they are rough and irregular. Current flows across constricted areas where these rough surfaces make contact. Our aim in this paper is to optimize the above mentioned factors in order to achieve excellent joint efficiency and zero hot spots in switchgears.

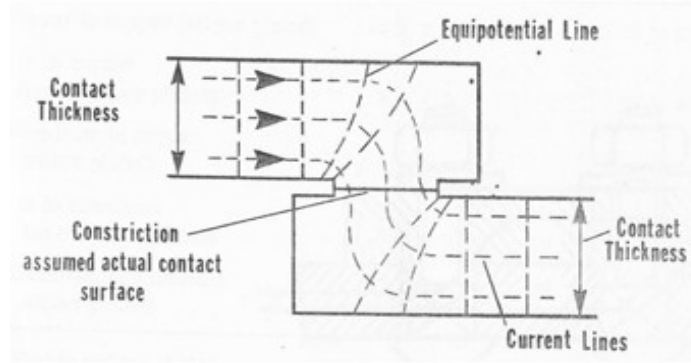

Fig. 1. Current flows across constricted areas [3]

\section{Problem Formulation}

Following bus bar combinations are considered in this paper for measuring contact resistance.

a) Bare Aluminum busbar and Bare Aluminum busbar

b) Bare Copper busbar and Bare Copper busbar

c) Buffed Aluminum busbar and Buffed Aluminum busbar

d) Buffed Copper busbar and Buffed Copper busbar

e) Silver plated Copper busbar and Silver plated Copper busbar

In each case milli-volt drop across the busbar joints at different loads will be measured. Lower the voltage drop lower will be the contact resistance for the same load.

Different factors [4] that will determine the efficiency of the joint with possible remedies are as follows:

a) Streamline effect

b) Effect of oxides in contact resistance

c) Condition of the contact surfaces

\section{A. Streamline Effect:}

The distortion of the lines of current flow at an overlapping joint between two conductors affects the resistance of the 
joint. In case of an overlapping joint between two flat copper bars the streamline effect is dependent only on the ratio of the length of the overlap to the thickness of the bars and not on the width. Hence the efficiency of an overlapping joint does not increase as the length of the overlap increases and from the electrical point of view no advantage is to be gained by employing an unduly long overlap.

The resistance ratio e in fig -2 is the ratio of the resistance of a joint due to streamline effect Rs, to the resistance of an equal length of single conductor $\mathrm{Rb}$ :

$$
e=\frac{R s}{R b}=\frac{a b}{\rho l} R s
$$

where $\mathrm{a}=$ breadth of bar in $\mathrm{mm}$.

$\mathrm{b}=$ thickness of bar in $\mathrm{mm}$.

$\mathrm{l}=$ length of overlap in $\mathrm{mm}$.

$\rho=$ resistivity of the conductor, $\mu \Omega \mathrm{mm}$.

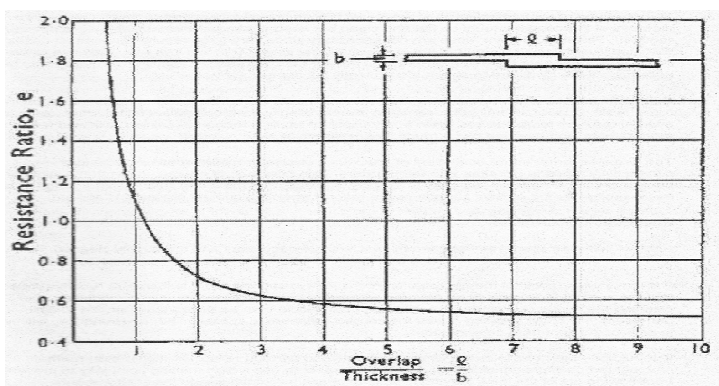

Fig. 2. Streamline effect in overlapping joints

From the graph it can be seen that the effect falls very rapidly for ratios to two and then very much slowly for values up to seven. This means that in most cases the streamline effect has very little effect as the overlap is of necessity much greater than seven.

\section{B. Effect of Oxides in Contact Resistance:}

In free air, oxide layers form [5] on the contact surfaces. Petroleum greases are used to slow down the formation of oxide layers. If the petroleum layer is very thin the contact resistance is negligible or nearly equal to the resistance in a vacuum.

Holm [6] determined that the contact resistance can be neglected if the thin film layer is less than $10^{-6} \mathrm{~cm}$ thick. He termed this layer quasimetallic. The low resistance can be explained by tunnel effect. Electrons can penetrate the thin film without energy loss, as if they are passing through a tunnel. If the layer is thicker, electrons lose energy and the resistance to current flow increases.

If there is a thick film on the contact surfaces, there is additional resistance present. The extra resistance is known as Fritting Resistance Rf. This occurs when the petroleum coating is greater than $10^{-6} \mathrm{~cm}$ thick or an oxide or sulfide film develops on the contacts. This thick layer can be penetrated if the electrical field force is great enough. Field strengths of $10^{-5}$ to $10^{-7} \mathrm{~V} / \mathrm{cm}$ will overcome this thick layer. This breakdown is known as a fritting. Once the thick layer begins to dissolve, the area of spot contact begins to increase and the resistance is lowered. The second step is called B fritting. Most power contacts have sufficient electrical fields to cause both $\mathrm{A}$ and $\mathrm{B}$ fritting. Therefore, the contact resistance is temporarily low, as if only a thin film is present.

This oxide formation can rapidly destroy unplated copper contacts. Silver plated contacts [7] are more resistant to the formation of this oxide film since silver does not form a stable oxide. Contact surfaces should be flattened by machining and thoroughly cleaned before carrying out silver plating. However if sulphides are present in the environment, a thick sulphide film will form on silver contacts.

\section{Condition of the Contact Surfaces:}

The condition of the contact surfaces of a joint [8] has an important bearing on its efficiency. The surfaces of the copper should be flat and clean. A microscopic view of the contact surfaces shows that they are rough and irregular as shown in fig -3 . Current flows across constricted areas where these rough surfaces make contact [9].

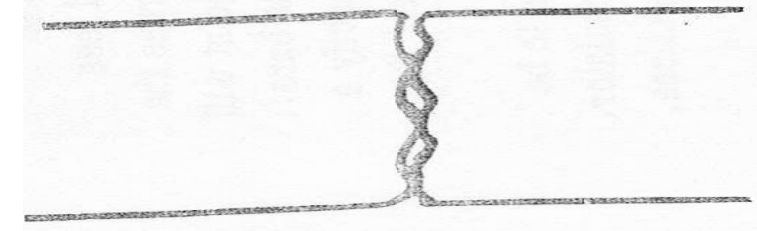

Fig. 3. Magnified contact surface [3]

The surface area of the constrictions depends on:

i) Hardness of the material

ii) Amount of contact force.

\section{Hardness of the Material:}

Contact hardness is expressed by the amount of force needed to cause permanent deformation.

Contact hardness is determined by pressing a round ball into the surface of the contact. The pressure causes the surface to deflect a certain distance while a load is applied. After the pressure is removed, a permanent indentation is left in the surface. The difference between the two lines of deflection $\mathrm{d}$ is the elastic deformation. The depth of the permanent deflection is the plastic deformation D. (fig-4)

The contact hardness is expressed by the amount of force needed to cause permanent deformation. For a radius of ball r. $\quad D=\frac{d}{r}$

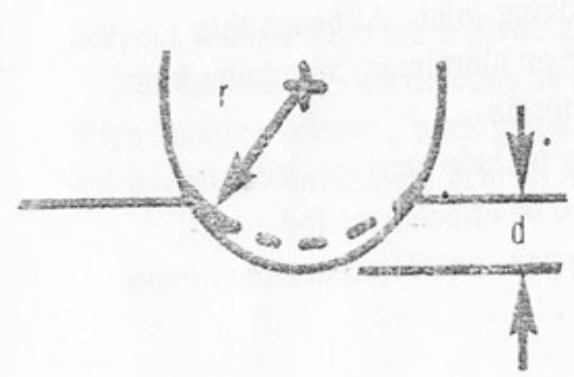

Fig. 4. Determination of contact hardness. [3]

\section{E. Amount of Contact Force:}

Contact resistance is dependent more on the total applied pressure than on the area of contact. If the total applied pressure remains constant and the contact area is varied, the total contact resistance remains practically constant. This can 
be expressed by the following equation:

$$
R i=\frac{C}{p \quad n}
$$

where

$$
\begin{aligned}
& \mathrm{Ri}=\text { resistance of the contact. } \\
& \mathrm{P}=\text { total contact pressure. } \\
& \mathrm{n}=\text { exponent between } 0.4 \text { and } 1 . \\
& \mathrm{C}=\text { a constant. }
\end{aligned}
$$

The greater the applied total pressure the lower will be the joint resistance [10] and therefore for high efficiency joints high pressure is usually necessary. The Fig-5 shows the effect of pressure on joint resistance.

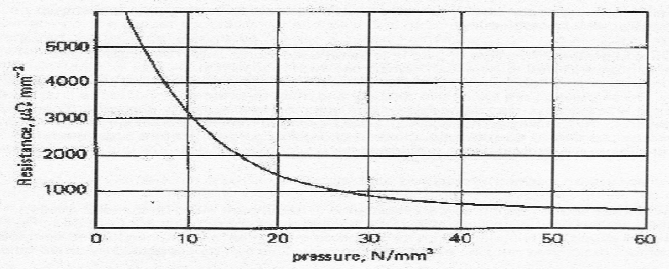

Fig. 5. Effect of pressure on contact resistance of a joint between two copper conductors

The joint resistance falls rapidly with increasing pressure, but above a pressure of about $15 \mathrm{~N} / \mathrm{mm} 2$ there is little further improvement [11]. These busbar joint may heat up under load as the contact pressure applied with steel bolts tends to increase because of the difference in expansion coefficient between two dissimilar metals, copper and steel. The temperature of the joint increases due to wattage loss and then decreases when the source is disconnected. Such repeated thermal expansions and contractions of dissimilar metals will vary the contact force and eventually will cause loose joints. To compensate for these changes, spring pressure should be added to this joint. Belleville washers [12] are frequently used to compensate for thermal expansion and contraction in clamped joints. It is important that these washers are not over stressed. Fig- 6 shows a bolted joint with Belleville washer

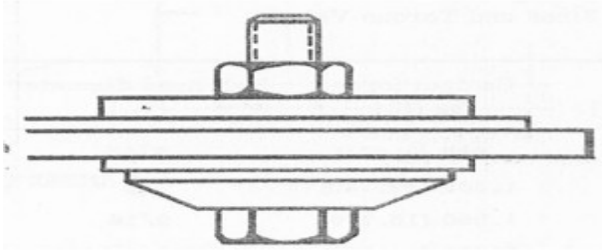

Fig. 6. Belleville washer in a bolted joint [3]

The following method can be used to calculate the size and material properties of Belleville washers (Refer Fig-07 \& Fig-08). Load and stress are calculated according to the following equations:

F(load)

$$
=\frac{\mathrm{E}_{\mathrm{f}}}{\left(1-\sigma^{2}\right) \mathrm{M}\left(\mathrm{D}_{2} / \mathrm{D}_{1}\right)^{2}}\left[\left(\mathrm{~h}-\frac{\mathrm{f}}{2}\right)(\mathrm{h}-\mathrm{f})\left(\mathrm{t}+\mathrm{t}^{3}\right)\right]
$$$$
\mathrm{h}=\frac{\operatorname{MS}\left(\mathrm{D}_{2} / \mathrm{D}_{1}\right)^{2}\left(1-\sigma^{2}\right)}{\mathrm{EfC}_{1}}+\frac{\mathrm{f}}{2}+\frac{\mathrm{C}_{2}}{\mathrm{C}_{1}} \mathrm{t}
$$

where

$$
\mathrm{F}=\text { load, } \mathrm{lb}
$$

$\mathrm{S}=$ stress, psi at the inside diameter.

$\mathrm{f}=$ deflection, in

$\mathrm{t}=$ thickness, in.

$\mathrm{E}=$ modulus of elasticity of material, $30 \times 10^{6} \mathrm{psi}$

$\sigma=$ Poissons ratio for material ( 0.3 value for steel)

$\mathrm{h}=$ height, in.

D1 = inner diameter, in.

$\mathrm{D} 2$ = outer diameter, in.

Washer dimensions are shown schematically in fig-8. The constants $\mathrm{C} 1, \mathrm{C} 2$ and $\mathrm{M}$ can be taken from fig-7.

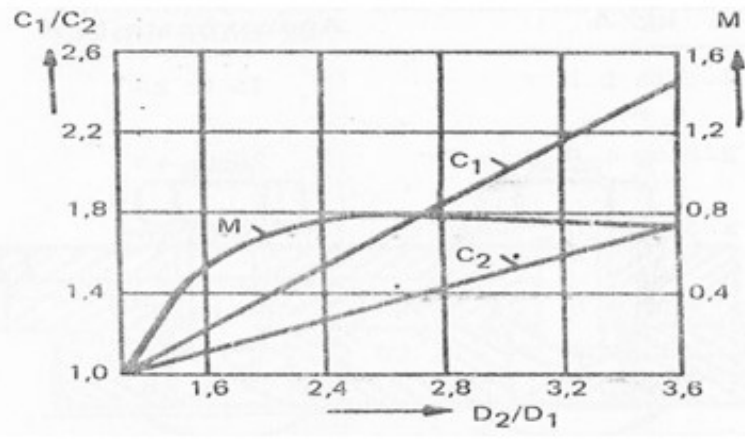

Fig. 7. Constants for equation related to belleville washer [3]

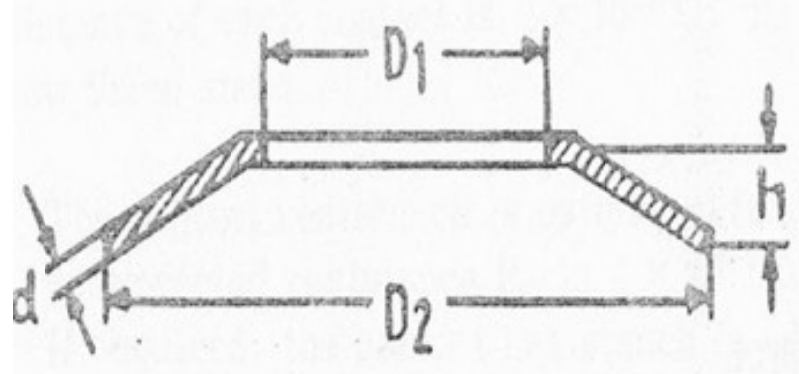

Fig. 8. Dimensions Of Belleville Washers [3]

\section{RESULTS BASED ON PRACTICAL EXPERIMENTS}

In the figures and the charts given below we are trying to compare results of the following busbar combinations at different loads varying from 100 Ampere to 603 Ampere. Here we are measuring voltage drop across the contacts. Lower the voltage drop lower will be the contact resistance.

a) Bare Aluminum busbar and Bare Aluminum busbar

b) Bare Copper busbar and Bare Copper busbar

c) Buffed Aluminum busbar and Buffed Aluminum busbar

d) Buffed Copper busbar and Buffed Copper busbar

e) Silver plated Copper busbar and Silver plated copper busbars.

Size of the bus bar in all the cases:

Length: $100 \mathrm{~mm}$, Width: $30 \mathrm{~mm}$, Thickness: $5 \mathrm{~mm}$

Overlap between two connecting busbars in all the cases:

Length: $30 \mathrm{~mm}$, Width: $30 \mathrm{~mm}$

Bolts used for jointing busbars:

Size : M10, MOC: MS with zink plated

Torque applied while connecting busbars in all the cases: $12 \mathrm{nM}$.

Thus in all these cases we have kept same overlap between the bus bars, applied optimum pressure and used Belleville washers. A thin film of petroleum coating was applied on each contact surfaces to avoid formation of oxide layer. 
Chart-1

\begin{tabular}{|c|c|c|c|}
\hline \multirow{2}{*}{\multicolumn{2}{|c|}{ Al-Al (Without Buffing) }} & \multirow{2}{*}{\multicolumn{2}{|c|}{ Al-Al (With Buffing) }} \\
\hline & & & \\
\hline Current (A) & $\mathrm{mV}$ & Current (A) & $\mathrm{mV}$ \\
\hline 100 & 14.1 & 118 & 9.7 \\
\hline 200 & 19.6 & 204 & 10.7 \\
\hline 300 & 25.4 & 307 & 12 \\
\hline 406 & 32.4 & 405 & 13.1 \\
\hline 503 & 39.1 & 526 & 17.8 \\
\hline 597 & 46.9 & 611 & 19.1 \\
\hline
\end{tabular}

Chart-2

\begin{tabular}{|c|c|c|c|}
\hline \multicolumn{2}{|c|}{$\mathrm{Cu}-\mathrm{Cu}$ (Without Buffing) } & \multicolumn{2}{c|}{$\mathrm{Cu}-\mathrm{Cu}$ (With Buffing) } \\
\hline Current (A) & $\mathrm{mV}$ & Current (A) & $\mathrm{mV}$ \\
\hline 103 & 13.5 & 105 & 9.3 \\
\hline 205 & 17.3 & 208 & 10.6 \\
\hline 310 & 21.7 & 300 & 11.8 \\
\hline 405 & 26.2 & 404 & 14 \\
\hline 506 & 31.1 & 510 & 15 \\
\hline 601 & 35.7 & 600 & 15.9 \\
\hline
\end{tabular}

Chart-3

\begin{tabular}{|c|c|}
\hline \multicolumn{2}{|c|}{ Cu-Cu (Silver Coated) } \\
\hline Current (A) & $\mathrm{mV}$ \\
\hline 107 & 9.1 \\
\hline 199 & 10.3 \\
\hline 302 & 11.6 \\
\hline 408 & 13.1 \\
\hline 508 & 13.9 \\
\hline 606 & 14.2 \\
\hline
\end{tabular}

In figs 9,10,11,12 $\mathrm{X}$ axis of the curve is showing current flowing through the bus bar joints and $\mathrm{Y}$ axis is showing milli-volt drop taking place in the joints. Lesser the milli-volt drop across a joint better will be the joint, as there will be lesser contact resistance, lower temperature rise and lesser power loss.
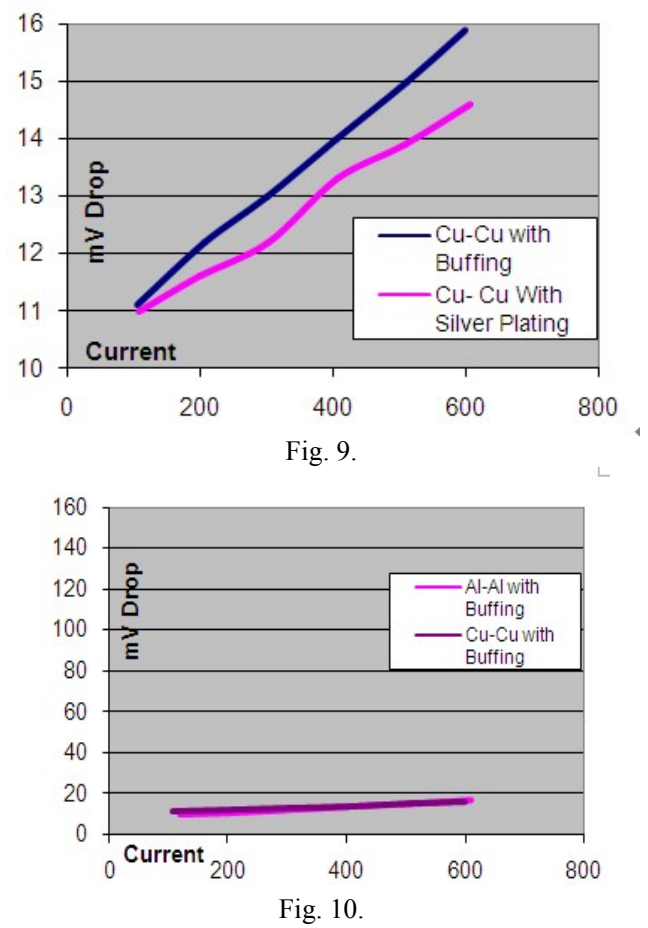
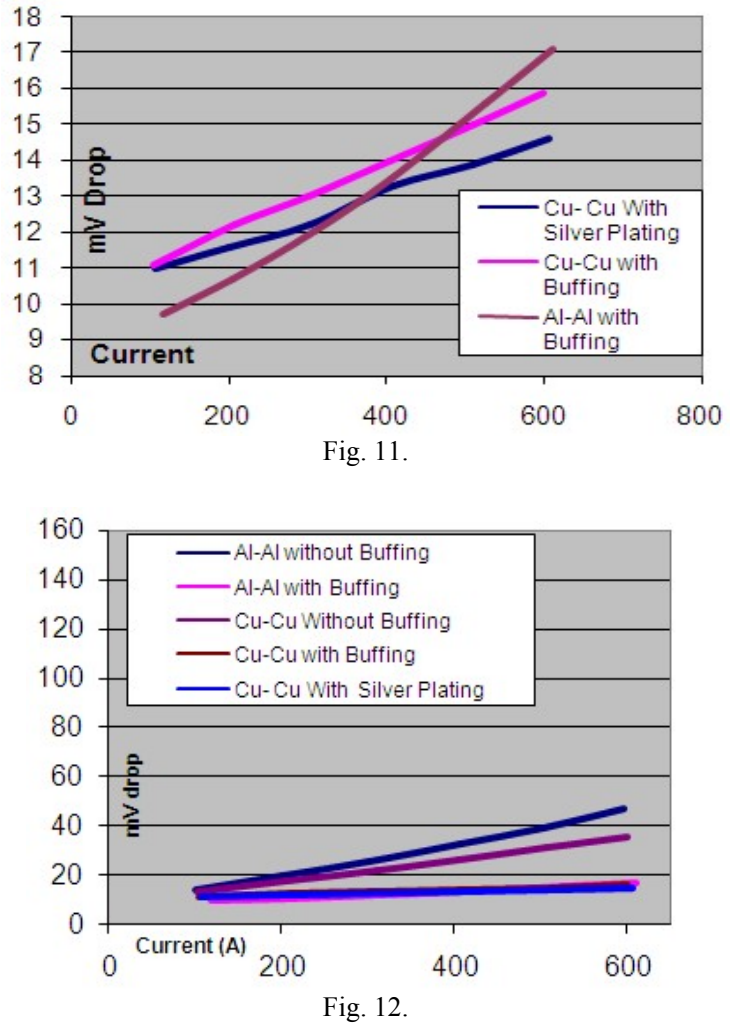

From the results shown in chart-1 we can see that joints between two buffed aluminum busbars are better then joints between two aluminum busbars which are not buffed.

In chart-2 we can see that joints between two buffed copper busbars are better then joints between two copper busbars which are not buffed. In chart-3 we can see that a buffed copper joint can be further improved by silver plating of the mating surfaces. This is shown in graphical form in fig-9.In Fig-10 we have compared the results between buffed aluminum joints and buffed copper joints.Fig-11 shows supremacy of silver plated copper joints over buffed aluminum joints and buffed copper joints.Fig-12 shows overall comparison of the all five cases considered in the experiment.

\section{CONCLUSION}

The performance of contact joint is dependent on maintaining low resistance. It is evident from the experimental results that by just smoothening or buffing the surface of both copper and aluminum busbars we can get very low resistance across a joint. This can be further improved by silver plating of the mating surfaces in copper busbars.

Minimum resistance in conductive joints can be achieved by using silver plated Copper busbars as compared to unplated bare bus bars while keeping other constraints like overlap between the bus bars, applied optimum pressure, size and type of washer, application of thin film of petroleum coating on contact surfaces unchanged. Buffing also helps to minimize contact resistance of the joints.

Stable and minimum contact resistance of joints will reduce the need for frequent maintenance, decrease overall downtime of equipment and maintenance costs and greatly reduce the risk of catastrophic failures. 


\section{REFERENCES}

[1] S. S. J. Kindersberger and H. Löbl “Joint Resistance of Busbar-Joints with Randomly Rough Surfaces ," Proceedings of the 21th Conference on Electrical Contacts 2002, Zurich,

[2] A.K. Sawhney, A Course In Electrical Machine Design ,2006. ch. 2

[3] F. W. Kussy and J. L. Warren, Design Fundamentals For Low-Voltage Distribution and Contro, Marcel Dekker Inc, 1987, pp.133-157..

[4] S. Bhattacharyya, A. Choudhury, and H.R. Jariwala, Department of Electrical Engineering, S.V. National Institute of Technology, Surat-395007, India. "High quality joints of copper bus bars" International Journal of Engineering Science and Technology Vol. 2(8), 3808-3815. 2010

[5] The Oxide Handbook, Ed. G. V. Samsonov, IFI/Plenum,N.Y.

[6] R Holm, Electrical Contacts, Springer-Verlag, New York (English version) 1967.

[7] H. B. Chudnovsky, "Degradation of Power Contacts in Industrial Atmosphere: Silver Corrosion and Whiskers," Proceedings of the $48^{\text {th }}$ IEEE Holm Conference on Electrical Contacts, 2002.

[8] R. L. Jackson, "Significance of surface preparation for bolted aluminium joints," IEE Proc. C, Gen, Trans. \&Distrib., 128,(2), pp. 45-54, 1981.

[9] W. O. Freitag, Electric Contacts, Illinois Institute of Technology, Chicago 1975, p. 17.

[10] J. L. Johnson and L. E. Moberley, Electrical Contacts, Illinois Institute of Technology, Chicago, 1975, p. 53.

[11] S. M. Garte, Electric Contacts,Illinois Institute of Technology,1976, p. 65.

[12] Almen and Laszlo, Belleville Washers, Trans. ASME, Vol. 58, 1936

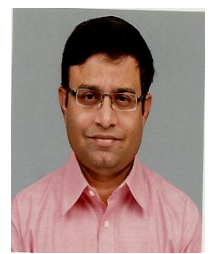

Samarjit Bhattacharyya received his B.E. (Electrical) degree from Jorhat Govt Engineering College Assam. Presently he is working in Reliance Industries Limited, HMD, Surat and also pursuing M-Tech in the Department of Electrical Engineering of S. V. National Institute of Technology, Surat. He is having more than 15 years of industrial experience.

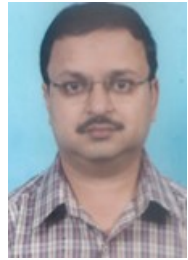

Hitesh R. Jariwala received his B.E.(Electrical) degree from S.V.Regional college of Engg. And Technology, Surat, India in 1989 and M.Tech degree from Indian Institute of Technology, Bombay, India in 2005 with specialization in Power Electronics and Power System. $\mathrm{He}$ is working as Associate Professor in Electrical Engineering Department, S.V. National Institute of Technology, Surat, India. His area of interest is Power system Dynamics, HVDC and FACTS.

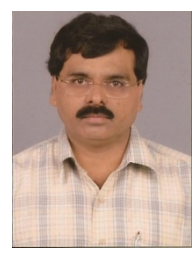

M Sharaschandra Shetty, received his BE in Electrical Engineering from MIT Manipal, University of Mysore, during the year 1984, Presently working as Head of Electrical (Engineering and Maintenance) at Reliance Industries Ltd., Hazira Manufacturing Division.

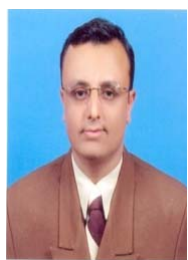

Rajulkumar Engineer received his BE in Electrical Engineering from SVNIT- Surat, Gujarat. Presently working as a Relay Testing and Protection Engineer at Reliance Industries Ltd., Hazira Manufacturing Division

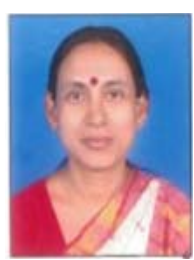

Anandita Chowdhury received her B.E. and M.E. degree from University of Calcutta, and Ph.D. degree from Indian Institute of Technology, Kharagpur. Presently she is working as an Associate Professor in the Department of Electrical Engineering of S. V. National Institute of Technology, Surat, India. She is having more than nineteen years of teaching experience. Her area of research interest includes Electrical Machines, Drives and Power system Stability. 